\title{
M. Sandras, Idées de la poésie, idées de la prose
}

\section{Germana Berlantini}

\section{(2) OpenEdition}

\section{Journals}

\section{Edizione digitale}

URL: http://journals.openedition.org/studifrancesi/10091

DOI: 10.4000/studifrancesi. 10091

ISSN: 2421-5856

\section{Editore}

Rosenberg \& Sellier

\section{Edizione cartacea}

Data di pubblicazione: 1 août 2017

Paginazione: 415-416

ISSN: 0039-2944

\section{Notizia bibliografica digitale}

Germana Berlantini, «M. Sandras, Idées de la poésie, idées de la prose», Studi Francesi [Online], 182 (LXI | II) | 2017, online dal 01 août 2017, consultato il 13 janvier 2021. URL: http://journals.openedition.org/ studifrancesi/10091; DOI: https://doi.org/10.4000/studifrancesi.10091

Questo documento è stato generato automaticamente il 13 janvier 2021.

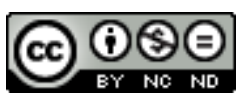

Studi Francesi è distribuita con Licenza Creative Commons Attribuzione - Non commerciale - Non opere derivate 4.0 Internazionale. 


\title{
M. Sandras, Idées de la poésie, idées de la prose
}

\author{
Germana Berlantini
}

\section{NOTIZIA}

MICHEL SANDRAS, Idées de la poésie, idées de la prose, Paris, Classiques Garnier, 2016, 501 pp.

1 Il volume di Michel SANDRAS nasce dalla constatazione della problematicità del rapporto fra prosa e poesia; un rapporto che, sebbene attraversi la letteratura fin dall'antichità, è stato raramente oggetto di interrogazioni rigorose e anche ai nostri giorni è caratterizzato dalla difficoltà di stabilire una precisa linea di confine. Fra poesia e prosa il regime di scambi storici è stato costante e tuttavia la distinzione fra le due nozioni resta irrinunciabile per comprendere tanto la produzione critica dei secoli passati quanto le singole opere. L'ipotesi che avanza Sandras è che ad ogni epoca la prosa si scriva in relazione a un'idea dominante di poesia, mediante dialoghi più o meno stretti, prestiti o differenze esplicitamente rivendicate. A questo scopo lo studioso prende in conto non solo i tratti stilistici peculiari a entrambe, ma anche le categorie estetiche e assiologiche elaborate dalla critica e dalla scrittura teorica. Il volume prende in considerazione prevalentemente la letteratura francese del xIX e Xx secolo, sebbene non manchino i riferimenti a secoli precedenti o ad altre letterature nazionali coeve (ad esempio a Wordsworth, Goethe, Hegel).

Dopo un breve avant-propos (pp. 7-12), l'introduzione (pp. 13-25) espone la tesi di Sandras sui rapporti reciproci di prosa e poesia, esemplificata dalla nozione propria alla fisica quantistica di intricazione (o entanglement) e declinata nel contesto di due casi specifici. In primo luogo il rapporto della prosa di Flaubert col poetico è analizzato alla luce delle oscillazioni che lo caratterizzano o, per meglio dire, dell'ambivalenza caratteristica di una scrittura prosastica dalla scansione talvolta poetica che non si esime dal ridicolizzare lo stereotipo dello slancio elegiaco. Il secondo esempio riguarda 
la poesia di Jude Stefan e Jacques Réda e le contaminazioni con la scrittura in prosa che vi intervengono.

3 Seguendo un ordine logico relativo all'argomentazione specifica (oltre a uno più generalmente cronologico), la prima sezione del volume è dedicata alla poesia («Représentations de la poésie et du poétique», pp. 29-177). Il primo capitolo, «Idées de la poésie» (pp. 29-80) è una sintesi delle sue principali rappresentazioni quali queste figurano in studi critici e storici o nei grandi dizionari. Le differenti nozioni che ogni epoca ricollega alla poesia, dal verso alla metafora, sono egualmente tenute in conto e analizzate sia in relazione al loro portato storico specifico sia, eventualmente, al carattere più generale che ne rende costante l'utilizzo attraverso i secoli. Il poetico viene declinato in rapporto sia al romanzesco (in continuità con gli studi di Jacques Rivière e Julien Gracq) sia alla nozione heideggeriana di evento. Il secondo capitolo della prima parte è intitolato "Quelques représentations du poétique au $\mathrm{xx}^{\mathrm{e}}$ siècle» ( $\mathrm{pp}$. 81-177). Dopo un'analisi della nozione di stampo formalista di "linguaggio poetico" quale questa ha orientato la maggior parte dei lavori nell'arco di tempo fra gli anni Sessanta e gli anni Ottanta, esso si articola nello studio di casi specifici: la sperimentazione di Jean Tortel, la lettura di Baudelaire fatta da Valéry, quella di Mallarmé ad opera di Blanchot, l'idea di poesia in Roland Barthes e infine l'esperienza dell'intravisto in Proust, Claude Simon e Jacques Réda.

4 La seconda parte del volume si intitola «Aspects de la prose littéraire (de Chateaubriand à Proust)» (pp. 181-324) ed è dedicata a dimostrare come la prosa letteraria si sia scritta (nel torno di tempo incluso fra l'opera dei due autori) in relazione all'idea dominante di poesia, acquisendo tratti poetici o affermando il proprio statuto autonomo. Dopo un capitolo introduttivo intitolato «Idées de la prose» (pp. 181-224) che ampio spazio dedica, fra gli altri temi, agli anni 1850-'60 e alla nascita con Flaubert e i Goncourt di una nuova prosa letteraria, il capitolo «Arts de la prose» (pp. 225-324) è dedicato allo studio della nozione di prosa d'arte in Gustave Lanson, alla storia e all'estetica della nuova forma letteraria del poema in prosa, all'opposizione di poetico e prosastico in Nerval, al problema del ritmo nella prosa di Michelet, a Merimée e alla sua lettura da parte di Walter Pater, a Proust.

5 La terza parte è infine intitolata «Formes d'hybridation au xxe siècle» (pp. 327-463) e si estende fino a includere le forme di ibridazione stilistiche del xxI secolo. Il fenomeno d'ibridazione più caratteristico, sul quale lo studioso focalizza maggiormente l'attenzione, è l'ibridazione o alleanza di scrittura critica e scrittura poetica, analizzata (assieme al rapporto di prosa e verso) nel primo capitolo («Formes hybrides contemporaines», pp. 327-360) oltre che nei casi specifici a seguire. Il secondo capitolo, «De Mallarmé à Philippe Jaccottet» (pp. 361-463), dedica due studi a Mallarmé seguiti dall'analisi di opere di Aragon, Michaux, Jacques Réda e Philippe Jaccottet.

6 La conclusione del volume (pp. 465-482) mobilitando Alain Badiou per sostenere la natura dinamica e variabile della percezione del poetico, legata al sentimento della lingua di una fase storica, trae le conseguenze dall'argomentazione svolta in favore di una pertinenza della distinzione prosa/poesia, tuttora valido e utile strumento critico malgrado le argomentazioni contrarie. La bibliografia (pp. 483-485) e gli indici (pp. 487-501) completano il volume. 